\title{
The Association of TLR4 and NOD2 Polymorphisms and Febrile Neutropenia in Children with Burkitt Lymphoma
}

\author{
Nihal OZDEMIR ${ }^{1}$, Mehmet GUVEN ${ }^{2}$, Bahadır BATAR ${ }^{2}$, Safa BARIS ${ }^{3}$, Ozlem TUN ${ }^{2}$, Tiraje CELKAN ${ }^{1}$ \\ ${ }^{1}$ Istanbul University Cerrahpasa Faculty of Medicine, Department of Pediatric Hematology-Oncology \\ ${ }^{2}$ Istanbul University Cerrahpasa Faculty of Medicine, Department of Medical Biology \\ ${ }^{3}$ Marmara University Cerrahpasa Faculty of Medicine, Department of Pediatric Immunology, Istanbul, TURKEY
}

\section{To the Editor}

Toll-like receptor (TLR) family regulates both innate and adaptive immune responses in humans. ${ }^{1}$ The first identified TLR polymorphism encodes an Asp299Gly amino acid substitution in TLR4. This polymorphism is associated with decreased signalling response to bacterial lipopolysaccharide. Previous studies have demonstrated that Asp299Gly and Thr399Ile polymorphisms cause an increased risk of gram-negative infections and systemic inflammatory response. ${ }^{1,2}$ TLR4 Asp299Gly and Thr399Ile were also shown to be associated with invasive aspergillosis.-5 Nucleotide-binding oligomerization domain-containing protein 2 (NOD2) is a member of a superfamily of genes which are involved in intracellular recognition of pathogens and expressed in intestinal epithelium, macrophages and dendritic cells. ${ }^{6}$ It was shown that NOD2 has synergistic effects on TLR mediated cytokine production and may modulate pathogen recognition by interracting TLR2 and TLR4 signalling. ${ }^{7}$ The two most common NOD2 variants are Arg702Trp and Gly908Arg. In the present study, the associations between TLR4 (Asp299Gly and Thr399Ile), NOD2 (Arg702Trp and Gly908Arg) mutations and the risk of febrile neutropenia $(\mathrm{FN})$ is investigated in children with Burkitt lymphoma (BL).
Between September 1995 and December 2007; 27 children with BL were enrolled in the study. The stages of patients were as following: Stage 1, n:1 (4\%), stage 2, n: 5 (19\%), stage 3, n: $11(40 \%)$ and stage 4, n: $10(37 \%)$. In our unit, BFM-B cell NHL-95 protocol is used in treating patients with BL since 1995 . Febrile neutropenia attacks (defined as fever $>38.5^{\circ} \mathrm{C}$ once, or $38^{\circ} \mathrm{C}>1 \mathrm{~h}$ with an absolute neutrophil count below $\left.0.5 \times 10^{9} / 1\right)$ and clinically documented severe mucositis during treatment periods were retrospectively analysed from patient files. Burkitt lymphoma cases and 110 age and sex matched healthy controls were investigated for TLR4 (Asp299Gly and Thr399Ile), NOD2 (Arg702Trp and Gly908Arg) genotypes using melting curve analysis on the LightCycler in blood specimens.

None of the 110 controls were found to have NOD2 (Arg702Trp and Gly908Arg) mutations, whereas TLR4 (Asp299Gly and Thr399Ile) genotypes were detected in 7/102 and 8/101 controls respectively. In the patient group, one child was heterozygous for the TLR4 Asp299Gly, two children were heterozygous for TLR4 Thr399Ile and one patient was heterozygous for both TLR4 polymorphisms (Asp299Gly and Thr399Ile). One child was heterozygous for NOD2 Gly908Arg polymorphism, while none showed NOD2Arg702Trp polymorphism. 
There was no statistical difference in the prevalance of polymorphisms between patients and controls. Of the 6 courses of chemotherapy, 54 FN attacks (mean $2 \pm 1.3$ attacks/patient) were detected in cases. The patient with carriage of the Gly299 allele died after the first FN episode due to sepsis and this was the only patient who expired due to infection, no pathogen could be identified from cultures. One patient with Thr399Ile allele carrier had FN after each 5/6 courses of chemotherapy and had severe mucositis in every episode. Klebsiella was isolated in two throat cultures of this patient. The patient who was heterozygote carrier of the Asp299Gly and Thr399Ile genotype also had FN in each 5/6 courses of therapy and severe mucositis. Candida albicans was isolated in one of the throat cultures of this patient. None of the cases had documented aspergillosis. The patients without mutations had 1-3 FN attacks/patient except one who had 5 FN attacks during the treatment.

The aim of this study was to investigate the impact of certain polymorphisms in TLR4 and NOD2 receptors on risk of neutropenic infections and mucositis. The study was limited by the small number of positive patients for TLR4 and NOD2 polymorphisms. However interestingly the only cases with carriage of the Gly299 allele was also the only patient who was lost due to sepsis. All carriers of investigated TLR4 mutations were found to have high rate of FN and mucositis compared to noncarriers. One patient who was heterozygous for NOD2 Gly908Arg did not have increased number of infections compared to non-carriers with BL. As NOD2 is known to have a synergistic effect on TLR mediated cytokine production, this was an expected result as that same patient was not found to have any accompanying TLR poylmorphism. The limiting factor of the study is the small sample size and the results should be interpreted with caution, other confounding factors such as stage, high dose chemotherapy and use of colony stimulating factors may also have an impact on increased the risk of FN. In conclusion, TLR4 polymorphisms may give a clue on individual risk factors of certain patients to FN and toxic effects of therapy. These are the preliminary results of our study and we plan to evaluate these correlations in larger groups of patients with childhood cancer.

\section{REFERENCES}

1. Lin YT, Verma A, Hodgkinson CP. Toll-like receptors and human disease: lessons from single nucleotide polymorphisms. Curr Genomics 13:633-45, 2012.

2. Mensah NY, Peterlongo P, Steinherz $P$, et al. Toll-like receptor 4 polymorphisms and risk of gram-negative bacteremia after allogeneic stem cell transplantation. A prospective pilot study. Biol Blood Marrow Transplant 15: 1130-3, 2009.

3. Bochud PY, Chien JW, Marr KA. Toll-like receptor 4 polymorphisms and aspergillosis in stem cell transplantation. N Engl J Med 359: 1766-77, 2008.

4. de Boer MG, Jolink H, Halkes CJ, et al. Influence of polymorphisms in innate immunity genes on susceptibility to invasive aspergillosis after stem cell transplantation. PLoS One 6: e18403, 2011.

5. Carvalho A, Pasqualotto AC, Pitzurra L, et al. Polymorphisms in toll-like receptor genes and susceptibility to pulmonary aspergillosis. J Infect Dis 197: 618-21, 2008.

6. Netea MG, Ferwerda G, de Jong DJ, et al. Nucleotide-binding oligomerization domain-2 modulates specific TLR pathways for the induction of cytokine release. J Immunol 174: 6518-23, 2005.

7. Kersse K, Bertrand MJ, Lamkanfi M, Vandenabeele P. NODlike receptors and the innate immune system: coping with danger, damage and death. Cytokine Growth Factor Rev 22: 257-76, 2011.

\section{Correspondence}

Dr. Nihal ÖZDEMIR

Istanbul Üniversitesi, Cerrahpasa Tip Fakültesi

Pediatrik Hematoloji-Onkoloji Anabilim Dali

Cerrahpasa

ISTANBUL / TURKEY

Tel: (+90.212) 4143000 (21482)

Fax: (+90.212) 6321282

e-mail: gnozdemir@hotmail.com 